\title{
Factors Related to Diabetes Self-Care Management Behaviors Among Patients with Type II Diabetes in Palestine
}

\author{
Rami Salem Abdelmajid Mosleh ${ }^{1 *}$, Yazun Bashir Jarrar ${ }^{2}$, Sa'ed Zyoud $^{3}$, Donald E. Morisky ${ }^{4}$ \\ ${ }^{1}$ Department of Pharmacy Practice, Faculty of Pharmacy, Universiti Teknologi MARA (UiTM), UiTM Puncak Alam, Selangor, Malaysia. \\ ${ }^{2}$ Department of Pharmacy, College of Pharmacy, AlZaytoonah University of Jordan, Amman, Jordan. \\ ${ }^{3}$ Department of Pharmacy, School of Medicine and Health Sciences, An-Najah National University, Nablus, Palestine. \\ ${ }^{4}$ Department of Community Health Sciences, UCLA Fielding School of Public Health, Los Angeles, California.
}

\section{ARTICLE INFO}

Article history:

Received on: 11/05/2017

Accepted on: 25/10/2017

Available online: 30/12/2017

Key words:

Self-care management, type

II diabetes, Palestine.

\begin{abstract}
This study aims to assess factors related to self-care management through conducting a cross-sectional study. A personal interview using structured questionnaires together with a medical records review sought information about socio-demographic, clinical characteristics, healthcare system factors, and self-care management. Univariate and multivariate analyses were carried-out by SPSS v16. Three hundred and thirty patients were recruited. The mean \pm standard deviation age of participants was $60 \pm 9.7$ years, $51.2 \%$ were male, $88.5 \%$ had additional chronic diseases, and $46.1 \%$ were obese. The multivariate analysis showed that being married, overweight, and obese were significantly related to decreased odds of follow diabetic meal plan, increased diabetes duration was significantly related to increased odds of follow diabetic meal plan. Increased number of additional chronic diseases was significantly related to decreased odds of physical exercise participation. Being married and not receiving insulin treatment were significantly related to decreased odds of self-blood glucose monitoring. Female participants were significantly related to decreased odds of medication adherence, and increased diabetes duration was significantly related to increased odds of medication adherence. Further investigation and improvement of inappropriate self-care management, and educational programmes would be of great benefit in achieving self-care management improvement.
\end{abstract}

\section{INTRODUCTION}

Diabetes mellitus is one of the most common noncommunicable chronic diseases. Already of epidemic proportions, it has become a public health challenge world wide priority (Alberti and Zimmet, 1998). Its chronic nature and

\footnotetext{
* Corresponding Author

Rami Salem Abdelmajid Mosleh, Department of Pharmacy Practice Faculty of Pharmacy, University Teknologi MARA (UiTM)

UiTMPuncakAlam, 43600 Bandar PuncakAlam, Selangor, Malaysia. Tel: +603-32584835 Fax: +603-32584602

E-mail address: rami_musleh123@hotmail.com
}

devastating diabetic complications make it a very costly disease (Javanbakht et al., 2011). The Arab world accounted for the second largest share of the marked increase in the diabetes incidence and prevalence, consisting mainly of type II diabetes in both developed and developing countries (Shaw et al., 2010). Patient self-care management refers to the extent to which patient behaviors, such as following a diabetic meal plan and prescribed medication regimen, corresponds with recommendations from healthcare professionals (Krapek et al., 2004), while Wong et al. (2005) indicate that medication adherence is an active, individual, dynamic and continuous process. Diabetes self-care management include diet control, physical exercise, self-blood glucose monitoring, and medication adherence. 
Ideally, diabetes self-care management are consistent and proportionate to the extent possible and consistent with the patient lifestyle, so that the patient can adhere to a self-care management (Andreoli et al., 2010). Jamison et al. (2006) discussed various ways in terms of self-reports and examinations to measure self-care management items. Thus, the degree of follow a diabetic meal plan, physical exercise participation in at least 30 minutes daily, self-blood glucose monitoring, and medication adherence are self-care management assessment items among the study participants. Glycaemic control is a medical healthcare outcome that relies on patient self-care management. Other factors besides healthcare outcomes, whether medical or economic include a reliance on healthcare system factors. Hence, preventive education and other healthcare system factors may serve as additional related factors critical for proper self-care management and healthcare outcomes.

In Palestine, there is currently limited research about diabetes self-care management and a need to assess its relationship with other factors among type II diabetic patients. Thus, the question of how best to foster and facilitate diabetes self-care management is an especially important issue for healthcare providers in the country. Hence, this study has examined diabetes self-care management and its relationship with patient characteristics and healthcare system factors among patients with type II diabetes.

\section{METHODS}

\section{Study design}

This cross-sectional study focused on type II diabetic patients of the National Centre for Chronic Diseases and Dermatology in Ramallah city. The inclusion criteria for study participation were patients diagnosed with type II diabetes for one year or more, currently being under medical care for type II diabetes with available medical file at the centre, with at least two outpatient visits to the centre within the previous one year, and willing to sign the consent form and participate in the study.

A sample size was selected from a target population of 1200 patients using the Daniel formula based on the fact that there is no previous publication about self-care management for Palestinian diabetic patients, and the assumption of medication adherence rate in Palestine to be from $20 \%$ to $50 \%$ (Jamous et al., 2011; Zyoud et al., 2013).

The significance level is set as $\alpha=0.05$ (two-tailed) and a 95\% confidence interval (C.I), $Z$ value $=1.96$ for $95 \%$ C.I, precision $(\Delta)=0.05$, and the expected prevalence in the sample with the characteristic of interest (p) to be 0.5 (Daniel, 1999; Naing et al., 2006). An estimated 292 patients needed for this study. However, an adjusted sample size was calculated because the target population is less than 10,000. The calculation for the adjusted sample size $=\mathrm{n} /(1+(\mathrm{n} /$ population $))$, where $\mathrm{n}$ is the calculated sample size from the Daniel formula, generated a minimum sample size of 235 patients (Daniel, 1999; Singh and Masuku, 2014). The researcher recruited a minimum sample size of 247 patients in order to minimise erroneous results and increase the study reliability (Daniel, 2010).

\section{Ethical approval}

The study was approved by the Palestinian Ministry of Health (Reference No. 111/51), and the Research Management Institute (RMI) at Universiti Teknologi MARA (UiTM) (Reference No. 600-RMI). A signed consent form was obtained from the patients who agreed to join the study prior to its commencement.

\section{Data collection}

Socio-demographic, clinical diabetes-related characteristics, healthcare system factors, and self-care management profile of type II diabetic patients were five main variables used in the study. Data collection consisted of personal interviews and a medical records review for the past one year using a set of questionnaires and data collection forms. The main questionnaires and forms were Demographic and Health Questionnaire, Patient Perception of Diabetes Care Quality Questionnaire, Diabetes Professional Performance Checklist, SelfCare Management Scale; and Medical Records Checklist.

\section{Description of patient characteristics}

Participant characteristics were divided between sociodemographic and clinical diabetes-related characteristics. Sociodemographic items in the study included age, gender, marital status, income level, educational level, place of residence, and occupation. Clinical diabetes-related items included any additional chronic diseases, cardiovascular disease risk factors (body mass index and smoking status), the type II diabetes duration, and the number of medications.

\section{Assessment of healthcare system factors}

Healthcare system variables include disease management characteristics (prescribed medications, patient-healthcare professional facilitation, and healthcare collaboration) and professional factors (quality of follow-up, preventive education, and patient-healthcare professional relationship). Three items make up the patient-healthcare professional facilitation. The first item explains how often the physician made an appointment in advance of the upcoming visit. The second item concerns the average patient consulting time received during each visit to the physician. The last item includes the extent to which the physician checked the patient's appointment card during each visit. The first and third items was rated on a five-point scale that ranges from one (never) to five (always). The second item was rated on a sixpoint scale ranges from one (less than 30 minutes) to six (longer than four hours). The total score range from three to 16 .

Healthcare collaboration scale consists of three items that assess a referral by a physician to another facility specializing in a diabetes-related examination or advanced diabetes treatment $(0=$ never, $1=$ referral for special examination and/or referral for 
advanced treatment), referral to other healthcare professionals for diabetes education and/or assistance $(0=$ never, $1=$ referral to another healthcare professional for diabetes education or other assistance), and diabetes care home visits or phone consultations by healthcare professionals $(0=$ never, $1=$ once, $2=$ twice, $3=$ three times, $4=$ more than three times). The total score range from zero to six. Quality of follow-up was assessed by obtaining data from both the medical records by using a medical records checklist, and personal interviews using the Patient Perception of Diabetes Care Quality Questionnaire. The seven items for quality of follow-up included available last readings of glycosylated haemoglobin (HbA1c); fasting blood glucose; lipid profile; nephropathy assessment; and blood pressure measures, feet and fungus examination, and ophthalmoscope examination (Gudina et al., 2011; Kaur et al., 2015). The score for each item is 10, and the total score can range from 10 t0 70. Diabetes preventive education was also assessed by data collection through personal interviews via the Patient Perception of Diabetes Care Quality Questionnaire. Assessment questioning five items (diet education, exercise education, instructions about foot care, self-blood glucose monitoring, and smoking status). The score for each item is 10 , and the total score can range from 10 to 50 .

The patient-healthcare professional relationship was assessed using the Patient Satisfaction with Healthcare Professional Scale consisting of five items specifically referring to physician, four items for nurses, and four for dieticians. Each item was rated on a five-point scale range from one (never) to five (always). The potential scores range from six to 30 ; zero to 25 ; zero to 25 for physician, nurse and dietician, respectively. A score of zero is given if the participant did not receive any care and education by a nurse and/or a dietician, and Patient Satisfaction with Healthcare Professional Scale total score range from six to 80 .

\section{Assessment of self-care management}

Diabetes self-care management was assessed using a diabetes self-care management scale, which identified the degree of following a diabetic meal plan (follow a diabetic meal plan as recommended by dieticians three days or more in the previous seven days), frequency of physical exercise (walked at least 30 minutes daily for three days or more in the previous seven days), the self-blood glucose monitoring (performed home glucose monitoring for five days or more in the previous seven days), and eight questions of the Eight-Item Morisky Medication Adherence Scale (MMAS-8) for medication adherence assessment with seven yes/no questions and one question answered on a five-point Likert scale, and MMAS-8 total score range from zero to eight $\quad<6$ reflect medication non-adherence and $\geq 6$ reflect medication adherence) (Khattab et al., 2010; Morisky et al., 2008; Shrivastava et al., 2013; Zyoud et al., 2013).

The overall self-care management level can be assessed by calculating the cumulative percentage of the scale's items. The cumulative percentage of diabetes self-care management scale $<50 \%$ indicate an inappropriate level, and a cumulative percentage of diabetes self-care management scale $\geq 50 \%$ refers to an appropriate level.

\section{Statistical analysis}

Data were entered and analyzed using Statistical Package for the Social Sciences (SPSS, version 16). Data were described using mean \pm standard deviation (SD) and median (inter-quartile range: Q1-Q3) for continuous variables. Continuous variables were tested for normality using the Kolmogorov-Smirnov test. Binary logistic regression was used to assess statistical significance of the difference in the percentages of self-care management (coded as 1) according to independent variables. Multiple logistic regression was conducted using independent variables that showed significance in binary logistic regression to determine factors that are related to self-care management. The significance level was set at $\mathrm{p}-$ value $<0.05$.

\section{RESULTS AND DISCUSSION}

\section{Characteristics of the study participants}

A total of 330 patients were recruited. Socio-demographic and clinical diabetes-related characteristics of the participants are summarised in Table 1 . The mean \pm SD age was $60 \pm 9.7$ (range $=$ 28-85). More than half $(51.2 \%)$ of participants were male. More than a quarter $(28.5 \%)$ of the participants had an elementary educational level, more than half $(50.9 \%)$ of the participants had city residency, and the majority $(69.1 \%)$ had a low income level. Less than half $(46.1 \%)$ of participants were obese, and more than half $(62.7 \%)$ had been diagnosed with type II diabetes for longer than 10 years. The mean \pm SD number of medications taken on a daily basis was 6.4 \pm 2.9 (median=6; Q1-Q3: 5-8).

Table 1: Socio-demographic and clinical characteristics of the study participants $(\mathrm{N}=330)$.

\begin{tabular}{|c|c|c|c|}
\hline Item & Category & Frequency & $\%$ \\
\hline \multirow[t]{5}{*}{ Age } & $28-37$ & 9 & 2.7 \\
\hline & $38-47$ & 38 & 11.5 \\
\hline & $48-57$ & 109 & 33.0 \\
\hline & $58-67$ & 116 & 35.2 \\
\hline & $\geq 68$ & 58 & 17.6 \\
\hline \multirow[t]{2}{*}{ Gender } & Male & 169 & 51.2 \\
\hline & Female & 161 & 48.8 \\
\hline \multirow{5}{*}{$\begin{array}{l}\text { Educational } \\
\text { level }\end{array}$} & Elementary & 94 & 28.5 \\
\hline & College/university degree & 75 & 22.7 \\
\hline & High/secondary & 65 & 19.7 \\
\hline & Junior middle & 61 & 18.5 \\
\hline & None & 35 & 10.6 \\
\hline \multirow{4}{*}{$\begin{array}{l}\text { Marital } \\
\text { status }\end{array}$} & Married & 253 & 76.7 \\
\hline & Widowed & 52 & 15.8 \\
\hline & Single & 20 & 6.1 \\
\hline & Divorced & 5 & 1.5 \\
\hline \multirow[t]{4}{*}{ Work status } & $\mathrm{No} /$ Retiree & 226 & 68.5 \\
\hline & Yes & 104 & 31.5 \\
\hline & -Regular schedule and location & 70 & 21.2 \\
\hline & -Irregular schedule and location & 17 & 5.2 \\
\hline \multirow{2}{*}{$\begin{array}{l}\text { Health } \\
\text { insurance }\end{array}$} & Government health insurance & 306 & 92.7 \\
\hline & $\begin{array}{l}\text { Both government health insurance } \\
\text { and private health insurance }\end{array}$ & 24 & 7.3 \\
\hline \multirow{3}{*}{$\begin{array}{l}\text { Place of } \\
\text { residency }\end{array}$} & City & 168 & 50.9 \\
\hline & Village & 150 & 45.5 \\
\hline & Palestinian refugee camp & 12 & 3.6 \\
\hline
\end{tabular}




\begin{tabular}{|c|c|c|c|}
\hline Income & $<500 \mathrm{JDs}$ & 228 & 69.1 \\
\hline level & $500-1000 \mathrm{JDs}$ & 82 & 24.8 \\
\hline $\begin{array}{l}\text { (Jordanian } \\
\text { Dinars) }\end{array}$ & & 6.1 \\
\hline Total & 0 & 38 & 11.5 \\
\hline number of & 1 & 29 & 8.8 \\
\hline chronic & 2 & 48 & 14.5 \\
\hline \multirow{2}{*}{ diseases } & 3 & 49 & 14.8 \\
\hline & $\geq 4$ & 166 & 50.3 \\
\hline \multirow{3}{*}{$\begin{array}{l}\text { Body mass } \\
\text { index }\end{array}$} & Obese & 152 & 46.10 \\
\hline & Overweight & 119 & 36.10 \\
\hline & Normal & 59 & 17.90 \\
\hline \multirow{2}{*}{$\begin{array}{l}\text { Smoking } \\
\text { status }\end{array}$} & Non-smoker & 209 & 63.30 \\
\hline & Smoker & 121 & 36.70 \\
\hline \multirow{4}{*}{$\begin{array}{l}\text { Diabetes } \\
\text { duration }\end{array}$} & $>10$ Years & 207 & 62.70 \\
\hline & $6-10$ Years & 74 & 22.40 \\
\hline & 4-5 Years & 33 & 10.00 \\
\hline & $<4$ Years & 16 & 4.80 \\
\hline \multirow{4}{*}{$\begin{array}{l}\text { Number of } \\
\text { medications }\end{array}$} & 0 & 11 & 3.3 \\
\hline & $1-3$ & 41 & 12.4 \\
\hline & $4-6$ & 121 & 36.7 \\
\hline & $\geq 7$ & 157 & 47 \\
\hline
\end{tabular}

*1 US Dollar equals 0.70 Jordanian Dinar.

\section{Reported healthcare system factors}

Less than quarter (22.4\%) of participants received insulin, and $22.4 \%$ received oral hypoglycaemic drugs. A combination treatment, with oral hypoglycaemic drugs and insulin, was given to more than half of the participants (54.8\%). The mean \pm SD quality of follow-up score was $38.8 \pm 13.2$ (median=40; Q1Q3: 32.5-47.5). The reported mean \pm SD preventive education score was 33.1 \pm 16.1 (median=40; Q1-Q3: 20-50). The mean \pm SD patient-healthcare professional relationship and patienthealthcare professional facilitation scores were $38.5 \pm 15.9$ (median=30; Q1-Q3: 28-52) and 11.1 \pm 2.9 (median=12; Q1-Q3: 9-13), respectively. The mean \pm SD healthcare collaboration score was 1.6 \pm 0.9 (median=1; Q1-Q3: 1-2). The data concerning descriptive statistics of healthcare system factors is presented in Table 2.

Table 2: Descriptive statistics of healthcare system factors.

\begin{tabular}{|c|c|c|c|c|c|}
\hline Variable & $\mathbf{z}$ & 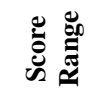 & & $\sum_{\bar{\Sigma}}^{\tilde{E}}$ & \% \\
\hline Quality of follow-up score & 330 & $0-70$ & 40 & 8.8 & 13.2 \\
\hline Preventive education score & 330 & $0-50$ & 40 & 3.1 & 16.1 \\
\hline $\begin{array}{l}\text { Patient-healthcare professional } \\
\text { relationship score }\end{array}$ & 330 & $7-80$ & 30 & 8.5 & 15.9 \\
\hline $\begin{array}{l}\text { Patient-healthcare professional } \\
\text { facilitation score }\end{array}$ & 330 & $3-16$ & 12 & 1.1 & 2.9 \\
\hline Healthcare collaboration score & 330 & $0-6$ & 1 & 1.6 & 0.9 \\
\hline
\end{tabular}

Abbreviations: $N$ Valid number; $S D$ Standard deviation.

\section{Reported self-care management}

More than half of the participants followed a diabetic meal plan $(55.2 \%)$ and participated in the physical exercise (54.2\%). However, more than a quarter (26.1\%) of the participants tested their blood glucose level at home, and the majority (72.4\%) were considered adherent, while more than a quarter (27.6\%) of the participants were non-adherent. The overall self-care management level was higher than the average (cumulative percentage $=52 \%$ ). This finding was higher compared to Omani study where the overwhelming majority of participants reported 'never' to the questions regarding following a diabetic meal plan, physical exercise, and self-blood glucose monitoring (Alrahbi, 2014). In addition, the medication adherence proportion was found to be higher by comparison with an Indian study (Arulmozhi and Mahalakshmy, 2014). Further, medication adherence was present in almost $41 \%$ of patients in Bharati hospital (Sajith et al., 2014). Other study reported that the majority of patients were nonadherent to self-care management (Kurtz, 1990).

Poor self-care management was reported to be a significant barrier to attaining positive medical health outcomes among type II diabetic patients in both developed and developing countries (Adisa et al., 2009). Previous studies identified glycaemic control barriers in terms of patient characteristics and healthcare system factors (Dalewitz et al., 2000; Hiss, 1996; Jerant et al., 2005; Nagelkerk et al., 2006). Others have identified selfcare management barriers (Sajith et al., 2014; Sweileh et al., 2014). This study is the first attempt to expand earlier studies by evaluating a comprehensive group of factors on diabetes self-care management.

\section{Factors relating to self-care management}

Univariate analysis shows that there was a significant relationship between following a diabetic meal plan and marital status, body mass index and diabetes duration. Married, overweight and obese participants were less likely to follow a diabetic meal plan ([O.R=0.5; 95\% C.I of 0.3-0.9] and [O.R $=0.4$; $95 \%$ C.I of $0.2-0.8]$ and [O.R $=0.3 ; 95 \%$ C.I of $0.2-0.6$ ] respectively). However, participants with a long diabetes duration were more likely to follow a diabetic meal plan ([O.R $=1.04 ; 95 \%$ C.I of 1.01-1.07]).

Multivariate analysis (Table 3) shows that marital status, body mass index and diabetes duration were significantly related to following a diabetic meal plan. Being married, overweight and obese were significantly related to decreased odds of following a diabetic meal plan. Married participants and those who were overweight and obese were less likely to follow a diabetic meal plan ([O.R $=0.52 ; 95 \%$ C.I of $0.30-0.90]$ and [O.R $=0.40 ; 95 \%$ C.I of $0.20-0.80$ ] and [O.R $=0.25 ; 95 \%$ C.I of $0.13-0.51$ ] respectively). However, increased diabetes duration was significantly related to increased odds of following a diabetic meal plan. Participants with a long diabetes duration were more likely to follow a diabetic meal plan ([O.R=1.05; 95\% C.I of 1.01-1.08]).

Follow a diabetic meal plan might have accounted for normal body mass index. A review of healthcare policies related to weight control could lead to glycaemic control improvement, ward off the related cardiovascular disease risk factors, and would be of great benefit in delaying progressive development of comorbidities. Therefore, continuous education is recommended to encourage patients to follow dietary restrictions. In addition, dieticians and other healthcare professionals should offer a diabetic meal plan that is acceptable and realistic for patients and their families, as well as ensure that they understand what they are supposed to do. 
Table 3: Multivariate analysis of factors related to following a diabetic meal plan.

\begin{tabular}{|c|c|c|c|c|c|}
\hline Variable & Coefficient ( $\beta$ ) & S.E & Wald & Odds Ratio with $95 \%$ C.I & P-Value \\
\hline \multicolumn{6}{|l|}{ Marital status } \\
\hline Single & & & & Reference (1) & \\
\hline Married & -0.66 & 0.28 & 5.44 & $0.52(0.30-0.90)$ & 0.020 \\
\hline \multicolumn{6}{|l|}{ BMI } \\
\hline Normal & & & & Reference (1) & \\
\hline Overweight & -0.93 & 0.36 & 6.63 & $0.40(0.20-0.80)$ & 0.01 \\
\hline Obese & -1.37 & 0.35 & 14.99 & $0.25(0.13-0.51)$ & $<0.001$ \\
\hline Diabetes duration & 0.05 & 0.02 & 7.89 & $1.05(1.01-1.08)$ & 0.005 \\
\hline
\end{tabular}

Abbreviation: S.E Standard error; C.I Confidence interval.

Table 4: Multivariate analysis of factors related to participation in physical exercise.

\begin{tabular}{|c|c|c|c|c|c|}
\hline Variable & Coefficient ( $\beta$ ) & S.E & Wald & Odds Ratio with 95\% C.I & $\bar{P}$-Value \\
\hline Number of chronic diseases & -0.12 & 0.05 & 5.20 & $0.89(0.80-0.98)$ & 0.023 \\
\hline Diabetes duration & -0.01 & 0.02 & 0.56 & $0.99(0.95-1.02)$ & 0.455 \\
\hline Number of medications & -0.05 & 0.04 & 1.38 & $0.95(0.88-1.03)$ & 0.241 \\
\hline \multicolumn{6}{|l|}{ Insulin treatment } \\
\hline Yes & & & & Reference (1) & \\
\hline No & 0.54 & 0.38 & 2.01 & $1.72(0.81-3.62)$ & 0.157 \\
\hline \multicolumn{6}{|l|}{ Anti-diabetic therapy } \\
\hline Monotherapy & & & & Reference (1) & \\
\hline Combination & -0.11 & 0.29 & 0.16 & $0.89(0.51-1.57)$ & 0.693 \\
\hline
\end{tabular}

Abbreviation: S.E Standard error; C.I Confidence interval.

Univariate analysis of factors related to participation in physical exercise showed that there was a significant relationship between participation in physical exercise and a number of chronic diseases, diabetes duration, the number of medications, use of insulin treatment, and the type of anti-diabetic treatment regimen. Participants with a high number of chronic diseases and long diabetes duration were less likely to participate in physical exercise ([O.R=0.8; 95\% C.I of $0.8-0.9]$ and [O.R $=0.95 ; 95 \%$ C.I of $0.93-0.98]$ respectively). Those with a high number of medications were less likely to participate in physical exercise ([O.R=0.920; 95\% C.I of $0.850-0.996])$. Those who did not receive insulin were more likely to participate in physical exercise ([O.R=2.7; 95\% C.I of $1.5-4.7]$ ), while those who were on a combination treatment with oral hypoglycaemic drugs and insulin were less likely to participate in it ([O.R $=0.5 ; 95 \%$ C.I of 0.4 $0.8]$ ). In the multivariate analysis (Table 4), the number of chronic diseases was significantly related to participation in physical exercise. An increased number of chronic diseases was significantly related to decreased odds of participation in physical exercise, and those with a high number of chronic diseases were less likely to participate in physical exercise ([O.R $=0.89,95 \%$ C.I of $0.80-0.98]$ ).

These findings reflect the fact that a longer diabetes duration possibly causes progressive impairment of insulin secretion with time, which makes a response to oral hypoglycaemic drugs unlikely and leads to using a combination treatment with oral hypoglycaemic drugs and insulin (United Kingdom Prospective Diabetes Study (UKPDS) Group, 1998). Therefore, patients who were treated using a combination treatment of oral hypoglycaemic drugs and insulin had a more progressive disease with additional chronic diseases which required more aggressive treatment (Al-Nuaim et al., 1998; Goudswaard et al., 2004; Khattab et al., 2010).

Most of the type II diabetic patients consider the importance of physical exercise as a part of diabetes self-care management. However, the presence of additional chronic diseases such as cardiovascular diseases and gout would limit the ability to seriously participate in physical exercise as part of their daily routine. Therefore, diabetic patients with additional chronic diseases cannot do routine exercise and this is reported by other studies to be significantly related to poor glycaemic control (Benoit et al., 2005; Lawton et al., 2005). Healthcare professionals could not blame the patients for not doing physical exercise because they have multiple chronic conditions that prevent them. They might advise the participants with additional chronic diseases to do light activities because those with multiple ailments could perform some. However, this deserves attention and needs further investigation.

There was a significant relationship between self-blood glucose monitoring and marital status, diabetes duration, and insulin treatment in the univariate analysis. Married participants were less likely to test their blood glucose level at home ([O.R=0.6; 95\% C.I of $0.3-1.0]$ ), while participants with long diabetes duration were more likely to test their blood glucose level at home ([O.R=1.04; 95\% C.I of 1.01-1.07]). However, those not on insulin treatment were less likely to test their blood glucose level at home ([O.R=0.3; 95\% C.I of 0.1-0.6]).

Multivariate analysis (Table 5) shows that marital status and insulin treatment were significantly related to self-blood glucose monitoring. Being married and not receiving insulin treatment were significantly related to decreased odds of selfblood glucose monitoring. Married participants and those who 
were not on insulin treatment were less likely to test their blood glucose level at home $([\mathrm{O} . \mathrm{R}=0.53 ; 95 \%$ C.I of $0.30-0.94]$ and [O.R=0.28; 95\% C.I of 0.12-0.66] respectively).

Treatment with oral hypoglycaemic drugs encourages patients to feel that they are in a safe zone, and assume that blood glucose meters are only given to those suffering from more advanced or serious diabetes cases, as opposed to those who were treated with insulin or combination treatment of oral hypoglycaemic drugs and insulin. This could be an initial indicator on how they thought. Diabetes management involves multiple interventions, with diabetes care utilizing different care and education items (Coster et al., 2000). Self-blood glucose monitoring may be based on the preventive education. Singh and Masuku (2014) stated that longer diabetes duration, less intensive therapy, being male, subject age, lower educational level, lower income, and smoking might serve as significant independent barriers to regular self-blood glucose monitoring. The study findings by Harris et al. (1993) interpreted that the absence of established self-blood glucose monitoring guidelines, psychosocial well-being and lack of its perceived importance by married participants and those who did not receive insulin, may have accounted for the low awareness level among them, which may negatively impact willingness to taking step to self-blood glucose monitoring. Regardless of a lack of relationship between preventive education and self-blood glucose monitoring, an educational programme that emphasizes the importance of regular blood glucose monitoring, standardization of training and advice, would be of great benefit in gaining an active patient commitment to diabetes self-care management. Univariate analysis of factors related to medication adherence showed that there was significant difference between adherers and non-adherers in gender and diabetes duration. Female participants were less likely to be adherent ([O.R=0.4; 95\% C.I of 0.2-0.7]). Participants with long diabetes duration were more likely to be adherent ([O.R=1.05; 95\% C.I of 1.00-1.10]). In the multivariate analysis (Table 6), both gender and diabetes duration were significantly related to medication adherence. Female participants were significantly related to decreased odds of being adherent, and compared to male participants, female participants were less likely to be adherent ([O.R $=0.40 ; 95 \%$ C.I of $0.22-0.72]$ ). Increased diabetes duration was significantly related to increased odds of being adherent. Participants who were diagnosed with type II diabetes for a higher number of years were more likely to be adherent ([O.R $=1.05 ; 95 \%$ C.I of 1.01-1.10]).

This significant relationship in the study is consistent with the findings of Lertmaharit et al. (2005). However, the results differed from another study which found that male participants were less adherent (Fitzgerald et al., 1995), while Senior et al. (2004) could not find a significant relationship between gender and medication adherence. It is possible that in Palestine, where family and societal aspects lead to depression and female diabetics are more likely to be more depressed than males, depression may be the main barrier to medication adherence. This needs to be evaluated (Seo and Min, 2005; Voils et al., 2005). Kaholokula et al. (2003) suggest that depression is a consequence of diabetes, that might extend to female patients and interfere with specific self-care management items which perhaps could be improved by the depression treatment. The relationship between educational level and patient-healthcare professional relationship was obvious, but also non-significant in medication adherence. Medical knowledge might be related to patient educational level. The degree of medication adherence did not significantly increase with a rising educational level. Non-educated (illiterate) patients cannot distinguish between medications and the negative effects from non-adherence. However, more educated patients tend to be more familiar and aware of medication non-adherence (Sweileh et al., 2005).Emotional support, respect and giving reassurance while treating patients as equal partners, fostering a healthy relationship that engenders patient trust in healthcare professionals in concert with positive responsiveness from physicians, nurses and pharmacists is positively reflected in medication adherence (Lawson et al., 2005). This emphasizes the need for patients follow-up to ensure that they remember the given information, and encourage them to keep up with the given treatment and advice.

Table 5: Multivariate analysis of factors related to self-blood glucose monitoring.

\begin{tabular}{|c|c|c|c|c|c|}
\hline Variable & Coefficient ( $\beta$ ) & S.E & Wald & Odds Ratio with $95 \%$ C.I & P-Value \\
\hline \multicolumn{6}{|l|}{ Marital status } \\
\hline Single & & & & Reference (1) & \\
\hline Married & -0.64 & 0.29 & 4.77 & $0.53(0.30-0.94)$ & 0.029 \\
\hline Diabetes duration & 0.01 & 0.02 & 0.31 & $1.01(0.97-1.05)$ & 0.577 \\
\hline \multicolumn{6}{|l|}{ Insulin treatment } \\
\hline Yes & & & & Reference (1) & \\
\hline No & -1.26 & 0.43 & 8.49 & $0.28(0.12-0.66)$ & 0.004 \\
\hline
\end{tabular}

Abbreviation: S.E Standard error; C.I Confidence interval.

Table 6: Multivariate analysis of factors related to medication adherence.

\begin{tabular}{lccccc}
\hline Variable & Coefficient $(\boldsymbol{\beta})$ & S.E & Wald & Odds Ratio with 95\% C.I & P-Value \\
\hline Gender & & & & Reference $(1)$ & \\
Male & & & & $0.40(0.22-0.72)$ & \\
Female & -0.92 & 0.30 & 9.52 & $1.05(1.01-1.10)$ & 0.002 \\
\hline Diabetes duration & 0.05 & 0.02 & 6.32 & 0.012 \\
\hline
\end{tabular}

Abbreviation: S.E Standard error; C.I Confidence interval. 


\section{CONCLUSIONS}

The overall self-care management level was appropriate. Marital status, body mass index and diabetes duration were significantly related to following a diabetic meal plan. The effect of participants with a high number of chronic diseases being less likely to participate in physical exercise, remains inconclusive, deserves attention and needs further investigation. The absence of established guidelines on self-blood glucose monitoring and the limited perceived importance among patients who took oral hypoglycaemic drugs may have accounted for self-blood glucose monitoring non-adherence. It is also possible that particular attention paid to depression could lead to an enhancement in medication adherence.

\section{ACKNOWLEDGEMENTS}

We would like to take this opportunity to express our thanks and gratitude to the faculty of pharmacy, and Institute of Research Management and Innovation (Academic and Research Assimilation Project Code 600-IRMI/DANA 5/3/ARAS (0116/2016)), UiTM, and the Palestinian Ministry of Health for all of the facilities and support have been given throughout the period of data collection in the National Centre for Chronic Diseases and Dermatology.

Conflict of Interests: The authors declare that they have no competing interest in this research study.

\section{REFERENCES}

Adisa R, Alutundu MB, Fakeye TO. Factors contributing to nonadherence to oral hypoglycaemic medications among ambulatory type 2 diabetes patients in Southwestern Nigeria. Pharm Pract (Granada), 2009; 7: $163-169$

Al-Nuaim AR, Mirdad S, Al-Rubeaan K, Al-Mazrou Y, AlAttas O, et al. Pattern and factors associated with glycaemic control of Saudi diabetic patients. Ann Saudi Med, 1998; 18: 109-112

Alberti KG, Zimmet PZ. Definition, diagnosis and classification of diabetes mellitus and its complications. Part 1: diagnosis and classification of diabetes mellitus provisional report of a WHO consultation. Diabet Med, 1998; 15: 539-553

Alrahbi H. Diabetes self-management (DSM) in Omani with type-2 diabetes. International Journal of Nursing Sciences, 2014; 1: 352359

Andreoli TE, Fitz JG, Benjamin I, Griggs RC, Wing EJ. 2010. Andreoli and Carpenter's Cecil Essentials of Medicine. London, United Kingdom: Elsevier Health Sciences.

Arulmozhi S, Mahalakshmy T. Self care and medication adherence among type 2 diabetics in Puducherry, Southern India: A hospital based study. J Clin Diagn Res, 2014; 8: UC01UC03

Benoit SR, Fleming R, Philis-Tsimikas A, Ji M. Predictors of glycaemic control among patients with type 2 diabetes: a longitudinal study. BMC Public Health, 2005; 5: 1-9

Coster S, Gulliford MC, Seed PT, Powrie JK, Swaminathan R. Self-monitoring in type 2 diabetes mellitus: a meta-analysis. Diabet Med, 2000; 17: 755-761

Dalewitz J, Khan N, Hershey CO. Barriers to control of blood glucose in diabetes mellitus. Am J Med Qual, 2000; 15: 16-25

Daniel WW. 1999. Biostatistics: A Foundation for Analysis in the Health Sciences. New York: John Wiley \& Sons.
Daniel WW. 2010. Biostatistics: Basic Concepts and Methodology for the Health Sciences. New Jersey: John Wiley \& Sons.

Fitzgerald J, Anderson R, Davis W. Gender differences in diabetes attitudes and adherence. Diabetes Educ, 1995; 21: 523-529

Goudswaard AN, Stolk RP, Zuithoff P, Rutten GE. Patient characteristics do not predict poor glycaemic control in type 2 diabetes patients treated in primary care. Eur J Epidemiol, 2004; 19: 541-545

Gudina EK, Amade ST, Tesfamichael FA, Ram R. Assessment of quality of care given to diabetic patients at Jimma University Specialized Hospital diabetes follow-up clinic, Jimma, Ethiopia. BMC Endocr Disord, 2011; 11: 1-9

Harris MI, Cowie CC, Howie LJ. Self-monitoring of blood glucose by adults with diabetes in the United States population. Diabetes Care, 1993; 16: 1116-1123

Hiss RG. Barriers to care in non-insulin-dependent diabetes mellitus. The Michigan experience. Ann Intern Med, 1996; 124: 146-148

Jamison DT, Breman JG, Measham AR, Alleyne G, M. C, et al. 2006. Cost-Effective Strategies for Non-Communicable Diseases, Risk Factors, and Behaviours. Priorities in Health. New York, United States of America: Oxford University Press.

Jamous RM, Sweileh WM, Abu Taha AS, Sawalha AF, Zyoud $\mathrm{SH}$, et al. Adherence and satisfaction with oral hypoglycaemic medications: a pilot study in Palestine. Int J Clin Pharm, 2011; 33: 10281035

Javanbakht M, Baradaran HR, Mashayekhi A, Haghdoost AA, Khamseh ME, et al. Cost-of-illness analysis of type 2 diabetes mellitus in Iran. PLoS One, 2011; 6: 1-7

Jerant AF, von Friederichs-Fitzwater MM, Moore M. Patients' perceived barriers to active self-management of chronic conditions. Patient Educ Couns, 2005; 57: 300-307

Kaholokula JK, Haynes SN, Grandinetti A, Chang HK. Biological, psychosocial, and sociodemographic variables associated with depressive symptoms in persons with type 2 diabetes. J Behav Med, 2003; 26: $435-458$

Kaur R, Kajal KS, Kaur A, Singh P. Telephonic consultation and follow-up in diabetics: impact on metabolic profile, quality of life, and patient compliance. North Am J Med Sci, 2015; 7: 199-207

Khattab M, Khader YS, Al-Khawaldeh A, Ajlouni K. Factors associated with poor glycaemic control among patients with type 2 diabetes. J Diabetes Complications, 2010; 24: 84-89

Krapek K, King K, Warren SS, George KG, Caputo DA, et al. Medication adherence and associated haemoglobin A1c in type 2 diabetes. Ann Pharmacother, 2004; 38: 1357-1362

Kurtz SM. Adherence to diabetes regimens: empirical status and clinical applications. Diabetes Educ, 1990; 16: 50-59

Lawson VL, Lyne PA, Harvey JN, Bundy CE. Understanding why people with type 1 diabetes do not attend for specialist advice: a qualitative analysis of the views of people with insulin-dependent diabetes who do not attend diabetes clinic. J Health Psychol, 2005; 10: 409-423

Lawton J, Peel E, Parry O, Araoz G, Douglas M. Lay perceptions of type 2 diabetes in Scotland: bringing health services back in. Soc Sci Med, 2005; 60: 1423-1435

Lertmaharit S, Kamol-Ratankul P, Sawert H, Jittimanee S, Wangmanee S. Factors associated with compliance among tuberculosis patients in Thailand. J Med Assoc Thai, 2005; 88 Suppl 4: S149-S156

Morisky DE, Ang A, Krousel-Wood M, Ward HJ. Predictive validity of a medication adherence measure in an outpatient setting. J Clin Hypertens (Greenwich), 2008; 10: 348-354

Nagelkerk J, Reick K, Meengs L. Perceived barriers and effective strategies to diabetes self-management. J Adv Nurs, 2006; 54: $151-158$

Naing L, Winn T, Rusli BN. Practical issues in calculating the sample size for prevalence studies. Arch Orofacial Sci, 2006; 1: 9-14

Sajith M, Pankaj M, Pawar A, Modi A, Sumariya R. Medication adherence to antidiabetic therapy in patients with type 2 diabetes mellitus. Int J Pharm Pharm Sci, 2014; 6: 564-570

Senior V, Marteau TM, Weinman J. Self-reported adherence to cholesterol-lowering medication in patients with familial 
hypercholesterolemia: the role of illness perceptions. Cardiovasc Drugs Ther, 2004; 18: 475-481

Seo MA, Min SK. Development of a structural model explaining medication compliance of persons with schizophrenia. Yonsei Med J, 2005; 46: 331-340

Shaw JE, Sicree RA, Zimmet PZ. Global estimates of the prevalence of diabetes for 2010 and 2030. Diabetes Res Clin Pract, 2010; 87: 4-14

Shrivastava SR, Shrivastava PS, Ramasamy J. Role of self-care in management of diabetes mellitus. Journal of Diabetes \& Metabolic Disorders, 2013; 12: 1-5

Singh AS, Masuku MB. Sampling techniques and determination of sample size in applied statistics research: an overview. International Journal of Economics, Commerce and Management, 2014; 2: 1-22

Sweileh WM, Aker O, Hamooz S. Rate of compliance among patients with diabetes mellitus and hypertension. An-Najah University Journal for Research - Natural Sciences, 2005; 19: 1-12

Sweileh WM, Zyoud SH, Abu Nab'a RJ, Deleq MI, Enaia MI, et al. Influence of patients' disease knowledge and beliefs about medicines on medication adherence: findings from a cross-sectional survey among patients with type 2 diabetes mellitus in Palestine. BMC Public Health, 2014; $14: 1-8$

United Kingdom Prospective Diabetes Study (UKPDS) Group. Intensive blood-glucose control with sulphonylureas or insulin compared with conventional treatment and risk of complications in patients with type 2 diabetes (UKPDS 33). UK Prospective Diabetes Study (UKPDS) Group. Lancet, 1998; 352: 837-853
Voils CI, Steffens DC, Flint EP, Bosworth HB. Social support and locus of control as predictors of adherence to antidepressant medication in an elderly population. Am J Geriatr Psychiatry, 2005; 13: 157-165

Wong N, Black HR, Gardin JM. 2005. Preventive Cardiology: A Practical Approach. New York, United States of America: McGraw-Hill Zyoud SH, Al-Jabi SW, Sweileh WM, Morisky DE. Relationship of treatment satisfaction to medication adherence: findings from a cross-sectional survey among hypertensive patients in Palestine. Health Qual Life Outcomes, 2013; 11:

\section{How to cite this article:}

Mosleh RSA, Aziz NA, Ali SM, Manan MM, Zyoud S, Shah IM, Jarrar YB. Factors Related To Diabetes Self-Care Management Behaviors Among Patients With Type Ii Diabetes In Palestine. J App Pharm Sci, 2017; 7 (12): 102-109. 